\title{
Animitas. Finitud, tiempo e imagen
}

\author{
Macarena Soledad González Franzani \\ Universidad de Chile \\ franzania@ug.uchile.cl
}

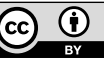

Fecha de recepción: 9-8-2020

Fecha de aceptación: 27-7-2021

\section{Resumen}

El siguiente trabajo sitúa a las animitas en el campo de la filosofía como un esfuerzo por comprenderlas desde una perspectiva complementaria a los trabajos que ya existen. Se trata de una búsqueda, un intento por atender a la profundidad de su sentido teniendo en cuenta su origen histórico y su función. El análisis se plantea desde una perspectiva filosófica que combina el estudio de las imágenes de la tradición alemana (Bohem y Belting) y la francesa (Bergson y Deleuze) para concluir que, en estos artefactos particulares de Chile y algunas regiones de Los Andes, la coefectuación entre el recuerdo y la imagen es radical.

Palabras clave: animitas; filosofía de la imagen; cuerpo; tiempo; materia

Abstract. Animitas: finitude, time and image

The following work locates animitas (roadside shrines to accident victims) in the field of philosophy in an effort to understand them from a perspective that complements existing studies. It is a search; an attempt to consider the depth of their meaning, taking into account their historical origin and function. The analysis takes a philosophical perspective that combines the study of images in both the German tradition (Bohem and Belting) and the French tradition (Bergson and Deleuze) before concluding that, in these particular artifacts from Chile and certain other regions of the Andes, the interplay between memory and image is radical.

Keywords: animitas; philosophy of image; body; time; material

\begin{aligned} & \multicolumn{2}{c}{ Sumario } \\ & Introducción Conclusión \\ & I Referencias bibliográficas \\ & II \end{aligned}




\section{Introducción}

La muerte que no admite que la sigan...

(Vicente Huidobro)

Cada grupo humano ha dado contenido a la eternidad de modo particular, de la misma manera en que ha elaborado un marco de sentido a su propia existencia individual y grupal. Cada grupo ha establecido también modos de relacionarse con los que ya han muerto y con esa eternidad sentida, modos de tratar con el cuerpo inerte y lidiar con la ausencia que queda como huella. Los muertos pasan a formar parte de los trasmundos que los vivos intuyen o creen intuir tras el mundo aparente, pero no se van del todo. En su lugar quedan las tumbas o las imágenes que los traen a presencia. Entre estas últimas, en Chile tenemos las llamadas «animitas» ${ }^{1}$.

Las animitas son «edículos, templetes, grutas, casitas y capillitas [que] se destacan en el paisaje rural y urbano de Chile, y [que] en su mayoría corresponden a lo que la sociedad chilena denomina como animita» (Ojeda, 2011: 70). Su masiva presencia en el territorio de Chile y en los Andes Centrales, su pregnancia, vigencia y permanente actualización las ha puesto en el centro de atención de diversos investigadores desde la segunda mitad del siglo xx. Gran parte de los resultados de dichas investigaciones - correspondientes en su mayoría al campo sociocultural- se traducen en los antecedentes de esta investigación de carácter filosófico, con la cual espero ampliar el conocimiento sobre estas imágenes mortuorias y contribuir al debate en torno a las imágenes.

Los estudios sobre animitas que he revisado son fundamentales para su comprensión, pues tal como señala Luis Bahamondes (2014): «los aportes de los enfoques socio-antropológicos, con el auge de los trabajos etnográficos, vinieron a reconocer el valor del testimonio oral y el contexto local en el que se desarrollan los hechos en pos de una explicación más rica en contenido y forma» (52). Desde esta perspectiva, el mismo autor, por ejemplo, vincula a la animita con la esperanza en el marco de la sociedad contemporánea:

En la sociedad actual, caracterizada como la era de la incertidumbre, la búsqueda de certezas y resguardo parece una constante. El proceso de exclusión de grandes sectores de la población que no poseen acceso a vivienda, salud, educación, además de contar con trabajos precarios, fortalece la sensación de desamparo y activa la búsqueda de soluciones eficaces e inmediatas, de manera alternativa o complementaria a los caminos oficiales. (Bahamondes, 2014: 41)

1. El presente artículo se centra en la comprensión de las animitas, sin embargo, el análisis que presento puede ser extensivo a otras imágenes de naturaleza votiva y ritual presentes en Latinoamérica y en otras partes del mundo. 
En un sentido similar, Lautaro Ojeda destaca su presencia como objeto de resistencia y apropiación espacial:

El valor de la animita como práctica y como objeto (desde la perspectiva del urbanismo y la arquitectura) consiste en poner en crisis varias prácticas institucionalizadas, normadas y estandarizadas. Las animitas como hologramas de la muerte imprevista dibujan una ciudad que se construye de forma paralela a la ciudad planificada racionalmente, creando un complejo sistema de signos, símbolos, prácticas y formas que muchas veces ponen en crisis la voluntad racional del Estado [...] podemos aseverar que estas cumplen un rol fundamental en lo que se refiere al uso y apropiación del espacio público, en cuanto se presentan como formas libres, que materializan un apego particular que cualifica y caracteriza de múltiples maneras una serie de lugares que inicialmente no tenían destino ni propósito. (Ojeda, 2011: 85)

No hay una institución que controle la práctica de la animita ni prescriba instrucciones para su realización. La esencia de la animita, señalan Ojeda y Torres (2011: 76), se halla en sus devotos: «[ellos] son sus diseñadores, sus constructores, sus cuidadores, sus restauradores», siendo la mímesis y la oralidad los medios por los cuales la animita se reproduce y se actualiza.

Pese a lo habitual que resulta verlas en Chile, las animitas son objetos complejos, cargados de simbolismos que los autores han querido indagar. Ricardo Salas señala (1992: 182):

A diferencia de una investigación meramente sociológica quisiéramos penetrar en el simbolismo fundamental subyacente a tales creencias. Se trata de contribuir a una "arqueología de la experiencia», en nuestro caso se trata de una experiencia de raigambre religiosa. Nuestra interpretación se ubica en un terreno que supone los datos de las ciencias sociales que dan cuenta del fenómeno religioso pero se ubica en un nivel más especulativo: se busca comprender el simbolismo inherente a las creencias y rituales relativos a la animita que veneran y recuerdan los habitantes pobres del Gran Santiago ${ }^{2}$.

En términos generales, los autores coinciden en señalar que los sentidos que se esconden en las animitas, como objeto y práctica transversal, se asientan en el complejo entramado de las creencias populares chilenas. En dicho entramado, con la muerte el alma abandona el cuerpo y se dirige a la eternidad. Para que esto ocurra, sin embargo, es necesario que la muerte se dé en determinadas circunstancias:

[...] es fundamental que esta separación sea serena, lo que requiere de un proceso de aceptación de la muerte y de un protocolo de despedida, durante el cual la persona libera toda carga angustiosa para retirarse de este mundo. La muerte abrupta y cruda elimina el proceso postergando y controlando el viaje al otro mundo, dejando al ánima en pena, que es condena, purga, desolación

2. Al respecto concuerdo con Ojeda y Torres (2011) cuando afirman que la animita no corresponde solo a una práctica de los más pobres. He encontrado ejemplos de ello en el desarrollo de la presente investigación. 
y errancia. El alma encallada ronda el sitio de los restos, vaga alrededor de su sangre, residuos de apego real y simbólico a la vida. (Lira, 2009: 23)

Esta idea de que la muerte violenta deja un alma en pena es común en el mundo occidental cristiano y se puede observar en la literatura, el cine y diversos programas de género periodístico que hacen referencia a fenómenos "paranormales» en lugares donde han ocurrido este tipo de fallecimientos.

En Chile y en algunos lugares de Perú esta muerte es conocida como «mala muerte» (Plath, 2012). En el mundo andino los lugares de la mala muerte eran temidos desde antes de la llegada de los españoles, pues se pensaba que «quedaban cargados con una energía fuerte, que emanaban fuerzas peligrosas y malignas» (Readi, 2016: 21). Esta creencia se mantiene hasta hoy, los riwutu (o 'almas tributantes'), víctimas de la tragedia, no pueden volver al origen: «Ellos están en este mundo para ayudar a los vivos en todas sus necesidades. Pero también necesitan ser atendidos debidamente» (Bascopé, 2001). Los lugares de una tragedia son señalados hasta hoy, en el desierto y el altiplano, con montículos de piedras que alertan a los viajeros de una presencia que no debe ser desestimada, que demanda ofrendas como hojas de coca o gotas de chicha: las apachetas, antepasados vigentes de las animitas.

Algo similar creyeron los hombres y las mujeres de la España medieval que levantaban cruces en los caminos (las encrucilladas) «para evitar la Santa Compañía (procesión de muertos o ánimas en pena que desde la medianoche caminaban errantes por los caminos, visitando hogares donde pronto moriría alguien)»(Lira, 2016: 81). En las encrucilladas, eran enterrados también los niños muertos sin bautizar.

De esta mixtura de creencias aparece la animita, cuya función describe Lira (2009: 20) de la siguiente forma:

La animita es un objeto que canaliza y materializa el anclaje del ánima; es ante todo un refugio que trastoca en parte su categoría de fantasma, apaciguándola, dándole la esperanza de cambiar su condición en el futuro; es un objeto mágico que circunscribe y protege el espacio sacralizado por la catástrofe; es una brújula que orienta al ánima, que sella un pacto de reverencia, de ayuda mutua entre ánima, deudos y devotos. También canaliza el dolor de los deudos a través de la presencia y el cuidado. Así, deviene en objeto religioso, facturado para administrar la transición del ánima hacia su lugar definitivo. Como tal, verifica la certeza de contacto con la trascendencia a través de la intermediación de este ser de transición, expresando la fe respecto de la posibilidad de comunicación entre vivos y muertos, ya que ella "escucha» las peticiones y oraciones de deudos y devotos.

La aparición de la animita comprende una serie de etapas que forman parte de la tradición sobre la cual se sustenta:

Su aparición no es instantánea, sino un proceso sujeto a los rasgos de la muerte acaecida. Los restos del fallecido y la sangre derramada son tratados ritualmente: los primeros son asumidos como lo entrañable, se recogen y acumulan en 
el sitio del suceso (como prueba del hecho) hasta quedar como elementos que acompañarán posteriormente a la animita. La sangre es una extensión de la vida del difunto que marca, demoniza y sacraliza el espacio. Ambos elementos son asistidos con profundo respeto y cuidado, pues se cree que el ánima queda prendida a ellos. (Lira, 2016: 76)

La idea de que la animita se levanta como refugio para el alma errante es compartida por los autores que han seguido los pasos de Claudia Lira. Sin embargo, en una reflexión posterior, la misma autora plantea la posibilidad de que se constituya como cuerpo para esa alma:

[...] con esa morfología en las formas, los colores y en las ofrendas, traté de dilucidar el sentido que tenía este objeto. Y entonces, bueno, está la muerte trágica, los referentes católicos, los referentes precolombinos de esa muerte trágica, la transformación del sujeto a partir de la materialización o de la crónica roja del sujeto, y de ahí los fui leyendo cada vez con más compresión, a partir de la morfología. Pero ahora, en términos estrictos, he llegado a la conclusión de que la animita, el objeto mismo, es un nuevo cuerpo para el alma. Entonces este nuevo cuerpo tiene ciertas características para producir el descanso y la serenidad de esa alma que está en pena y que está por tanto envuelta de tristeza, de angustia[,] que se requieren transfigurar para que su alma descanse. (Lira, 2015)

En el desarrollo de mis investigaciones he concluido que, en efecto, las animitas son más bien cuerpos, presencias sentidas que pueden interceder por los creyentes y obrar milagros. Respecto de esto último, Parker (1992) y Salas (1992) nos recuerdan el sacrificio y el significado de la sangre como aspecto fundamental de las prácticas religiosas en diversas culturas: «La noción de sacrificio surge en estrecha relación con este elemento asociado a la generación vital y corporal»(Salas, 1992: 185). También esta idea está presente en el cristianismo por medio del sacrificio del dios hecho hombre y de los mártires. Las víctimas de la "mala muerte» estarían más cerca del cielo, pues la tragedia y la sangre expiarían todos los pecados cometidos en vida (Ojeda y Torres, 2011; Bahamondes, 2014).

Finalmente, quisiera mencionar dos asuntos que me parecen importantes. Primero, el hecho de que cada animita contempla un espacio emocional o «de adherencia» (Ojeda y Torres, 2011) que se compone de elementos materiales e inmateriales:

Podemos aseverar que el espacio de adherencia es contradictoriamente sistémico, pues una animita es susceptible a crecer, decrecer o desaparecer, en función de los rituales que se le asocian. Esta frágil estabilidad formal es también su fortaleza, pues la renovación es un factor de atracción social, tanto para ser partícipe de los rituales como para contemplarla. (Ojeda y Torres, 2011: 75)

En segundo lugar, señalar que cada animita implica una experiencia única, pues «a pesar de tener patrones formales similares, resultan ser siempre diferentes, además de que cada una se esfuerza en distinguirse de otras animitas. 
Es decir, a pesar de su enorme cantidad, en Chile es muy difícil encontrar una que sea igual a otra» (Ojeda, 2013: 55) ${ }^{3}$.

La animita posee la condición de objeto (refugio/cuerpo), sujeto (alma/ presencia) y lugar (espacio de adherencia material e inmaterial), lo que le otorga un carácter polivalente (Ojeda, 2013) que se complementa con la noción de «holograma» desarrollada por Alicia Lindán (2007) con la finalidad de iluminar los aspectos invisibles que se hallan presentes en el espacio:

Según Lindán, las relaciones recíprocas entre espacio construido y espacio percibido, entre lo subjetivo y lo objetivo, lo material y lo inmaterial, lo individual y lo colectivo, lo furtivo y lo permanente, lo espacial y lo social, son cualidades estructurales e indisociables de la práctica de las animitas. (Ojeda, 2011:129)

Tenemos entonces «sujetos holográficos», «objetos holográficos» y «lugares holográficos», es decir, sujetos, objetos y lugares que invitan a preguntarnos por aquello que desborda su mera materialidad.

Figura 1. Lámina Esquema de polivalencia de las animitas

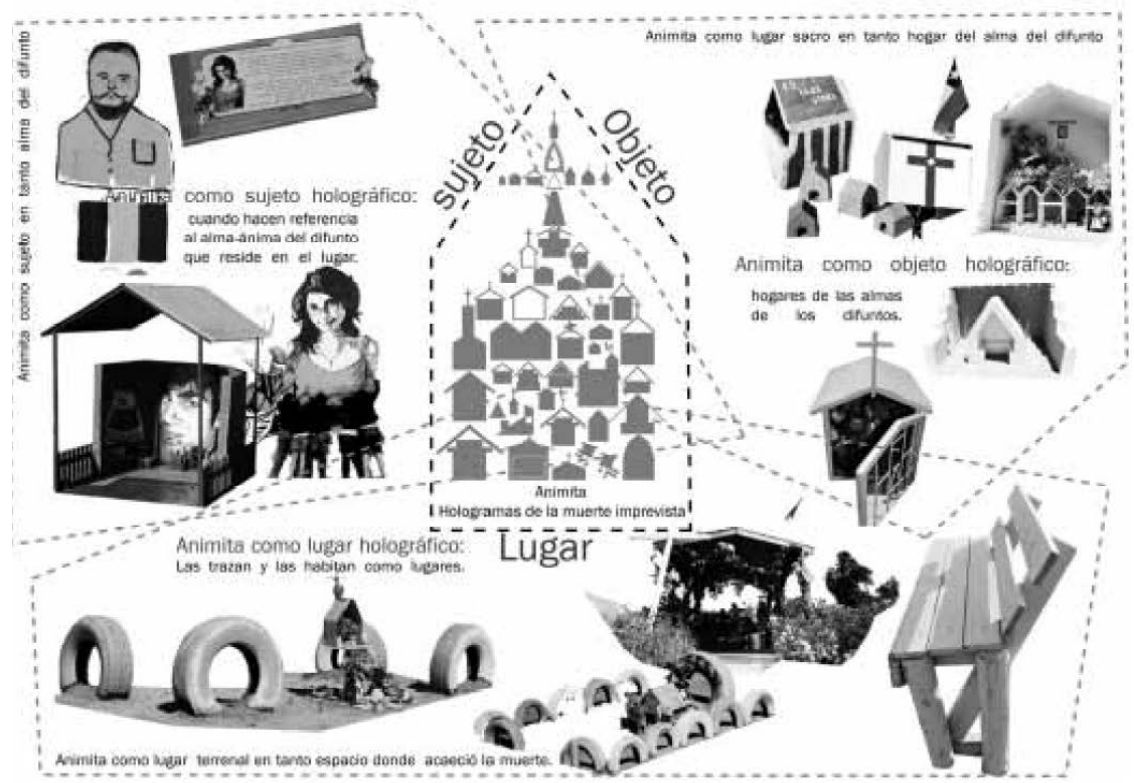

Fuente: Ojeda (2013: 64).

3. Ojeda (2011) identifica las formas más comunes, a las que denomina «arquetipos» —casa, iglesia, gruta, orgánica, cruces, modernas, sociales, monumentales e híbridas-. La noción de arquetipo aquí se refiere solo a la forma y no debe confundirse con el concepto de Jung, que hace referencia a imágenes asociadas a motivos universales con presencia transcultural. 
Pero ¿dónde reside el poder de las animitas para resistir a la modernización de las ciudades y la creciente laicización de la sociedad? ¿Cómo es que aún en medio del llamado «estallido social chileno» (octubre de 2019), mientras sucumbían iglesias y monumentos, ellas permanecieron incólumes?

Considerando los aportes de los estudios socioculturales y con la intención de complementar ese conocimiento desde otros enfoques, mi trabajo sitúa a las animitas en el campo de la filosofía en una incursión que busca comprenderlas por su condición de imagen, pues lo que las constituye como campos de fuerzas son su materialidad y pregnancia.

Figura 2. Tres momentos de la (bici)animita de Arturo Aguilera: en la tercera imagen, alguien ha compartido una copa de vino con él. Santa Isabel esquina Bustamante, Providencia, Santiago de Chile
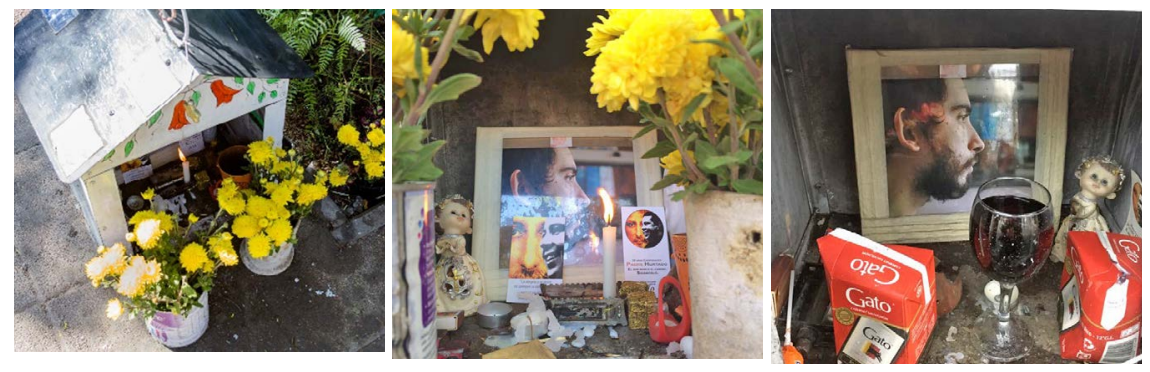

Fuente: fotografías de la autora.

Figura 3. Animitas de víctimas del estallido social de 2019, Santiago de Chile. Izquierda: Nacimiento de la animita de Mauricio Fredes. Irene Morales esquina Alameda Libertador Bernardo O'Higgins. Derecha: Animita de Jorge Mora Herrero, el Neco. Avenida Departamental esquina Exequiel Fernández
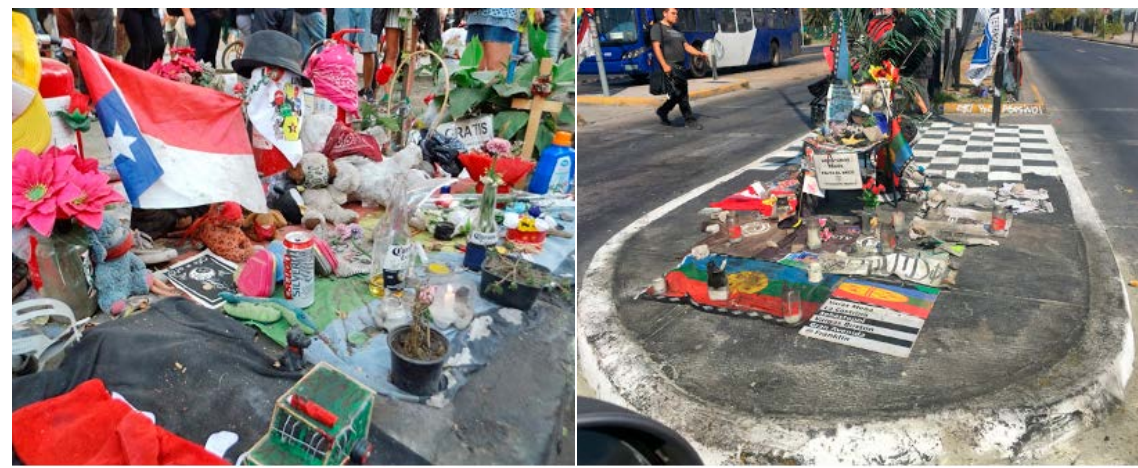

Fuente: (izquierda) fotografía de Sergio Urzúa, (derecha) fotografía de la autora. 
Figura 4. Animita de Valeska inserta en el frontis de una casa. Sector Bajos de Mena, comuna de Puente Alto, Santiago de Chile

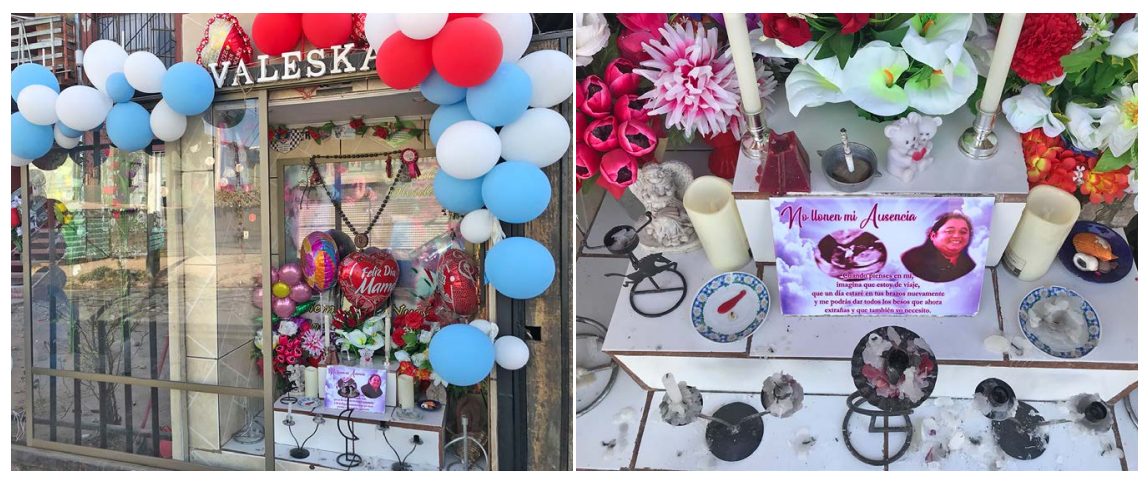

Fuente: fotografías de la autora.

Lo que constituye primariamente la esencia del alma no es otra cosa que la idea del cuerpo existente en acto.

(Spinoza, Ética III, Proposición III, Demostración)

Para un análisis de las animitas desde la filosofía comenzaré por una primera delimitación conceptual: las animitas son imágenes o artefactos icónicos por su capacidad de "explicitar sentido con medios visuales, es decir, por medio del mostrar» (Boehm, 2010: 67). De momento dejaré fuera las imágenes mentales o internas, pero solo de momento, pues, como pretendo demostrar, los artefactos visuales se entrelazan de tal forma con los cuerpos de sus productores y practicantes que toda separación es artificiosa, aunque necesaria para un primer análisis.

La perspectiva que he asumido para el estudio de las animitas como imágenes se enmarca en la discusión que ha tomado lugar en los espacios académicos desde la década de 1990 y que se arraiga en un renovado cuestionamiento a la superioridad del lenguaje frente a la multiplicidad ontológica de la experiencia humana, un proceso que ha traído consigo una vuelta a la presencia que había quedado oculta tras la búsqueda de significados (Moxey, 2009). En este contexto cabe mencionar dos autores clave: Mitchell, en el ámbito anglosajón, y Gottfried Boehm, en el mundo germano (García Varas, 2011). Ambos autores contravienen el modelo semiótico de orden lingüístico situándose en la "vida», la presencia existencial de las imágenes. Sin embargo, pese a tener preocupaciones similares, los enfoques y las metodologías de los Visual Studies donde participa Mitchell y la Bildwissenschaft impulsada por Boehm 
son diferentes (Moxey, 2009; García Varas, 2011). Para los Visual Studies el eje principal es la construcción cultural de la visualidad y la producción de subjetividades por medio de la producción, la circulación y el consumo de imágenes desde una perspectiva política y crítica. La Bildwissenschaft, en cambio, procura ir desde la imagen hasta sus hacedores y contextos de producción, situándose en las características y en las propiedades de la imagen desde una perspectiva filosófica y multidisciplinaria.

Mi trabajo tiene una preocupación y una metodología más cercana a la Bildwissenschaft, pues pone su acento en el poder que ejercen las imágenes y las múltiples relaciones que establecen con sus productores y agentes que las experimentan en distintos contextos, especialmente en los religiosos. Desde mi perspectiva, centrándose en las imágenes, el enfoque desarrollado por los autores de la corriente germana hace justicia a aquello que queda soslayado entre los pliegues de las narrativas dominantes o que se pierde en la imposibilidad de los códigos lingüísticos; lo que queda en silencio porque no se puede decir - lo prohibido, lo inapropiado, lo inefable-, pero que se arraiga en lo profundo de la experiencia y la memoria, y que, como un exceso interno de los cuerpos, se abre paso en la materia para ocupar un lugar más allá de ellos, prolongando y proyectando sus afectos.

De la Bildwissenschaft recojo la comprensión de la imagen en su singularidad como un logos no supeditado al lenguaje. Aunque ambos (imágenes y lenguaje) se encuentren imbricados de una u otra forma, el logos de la imagen, el sentido que instala, depende de su materialidad, su cromaticidad, las líneas y las sombras de, como señala Gottfried Boehm (2010), el juego discontinuo de sus contrastes:

Cada artefacto icónico se organiza en la forma de una diferencia visual, inteligente $y$ deíctica, es decir, no-linguiistica. Los aspectos constitutivos de las imágenes son diversos en cada caso, según se trate de pintura de cuevas, íconos, máscaras, cuadros, obras tridimensionales, dibujos, fotos, procedimiento de imágenes, diagramas o imágenes móviles. Pero todos estos casos coinciden en algo: en sus heterogéneas formas de aparición ellos activan un momento estructural que los vincula unos con otros y los convierte en imágenes. (Boehm, 2011)

De la Bildwissenschaft tomo también la mirada antropológica de Hans Belting, quien, situado en la praxis de la imagen en la historia de Occidente, pone en evidencia cómo el poder de las imágenes supera ampliamente los medios de la palabra, sobre todo en materias religiosas:

Las imágenes pasaban a ser rechazadas [por las autoridades religiosas] tan pronto como comenzaban a atraer más público que las instituciones mismas y a actuar por su parte en nombre de Dios. Su control con medios verbales era incierto, porque los santos llegaban a capas más hondas de la feligresía y cumplían deseos que los hombres vivos de la Iglesia no podían satisfacer. (Belting, 2009a: 9)

De esta manera, Hans Belting pone al centro de la discusión la antigua creencia en el poder taumatúrgico de las imágenes y la vida que poseen en 
determinados contextos. El poder de la imagen, sin embargo, no depende de sí misma, sino que se encuentra en relación con aquellas que residen al interior de los cuerpos de quienes las producen y experimentan. En el desarrollo de su trabajo, Belting (2015) afirma que la llamada «imagen mental» y la que está técnicamente producida se entrecruzan en el proceso de animación de las imágenes: «en su explicitación de esta idea, aboga por la tesis de que el auténtico "lugar de las imágenes" no es de ninguna manera, como alguien podría suponer, el museo, la pared o el cine, sino única y exclusivamente el "ser humano" (Wiesing, 2005: 23). El cuerpo humano es un lugar en el mundo, específicamente, un lugar donde se crean, se conocen o se reconocen las imágenes: «Sabemos que nuestros cuerpos ocupan lugares en el mundo, y que pueden regresar a ellos. Pero nuestros propios cuerpos representan también un lugar en que las imágenes que captamos dejan tras de sí una huella invisible» (Belting, 2009b: 73). Se trata de una relación recursiva.

La propuesta de Belting, sin embargo, no es nueva en la historia de la filosofía, ya Spinoza comprende el cuerpo y el alma como una identidad indisoluble modelada por múltiples afecciones, configurado como el espacio creador y de percepción de las imágenes (Ética, II. XVII, Escolio). Lo novedoso, quizás, tiene que ver con el origen y el sentido que encuentra en la producción de imágenes: «una imagen encuentra su verdadero sentido en representar algo que está ausente, por lo que solo puede estar ahí en la imagen; hace que aparezca algo que no está en la imagen, sino que únicamente puede aparecer en la imagen» (Belting, 2009b: 178).

Belting utiliza la palabra cuerpo para referirse a los cuerpos vivos de los agentes, como a los medios donde las imágenes se hospedan, tal vez como un modo de hacer énfasis en la magia de la imagen (Bildmagie) y su sentido presentativo. Detengámonos entonces en los cuerpos de los agentes, no sin considerar que nos encontramos en un terreno minado:

[...] será tema de interés biopolítico o anatomopolítico, delimitando los contornos de una población o su configuración individualizada (Foucault); o bien, tomado como centro de operaciones estético-políticas, señalará el límite de lo que forma parte o es excluido de una comunidad (Rancière, Buttler, Preciado); interpretado como campo de fuerzas, será el resultado de una «lógica de las sensaciones» que expresa tanto las violencias que en él confluyen (para constituirlo en unidad) como las torsiones, fugas y desvíos que lo expresan como multiplicidad irrepresentable (Deleuze, Lyotard); o bien, será el objeto que se disputan las enunciaciones que quieren inscribirlo según un orden normalizado de la lengua. (Ulm, 2018: 32)

Sin querer pasar por alto los escasos consensos que dominan la discusión actual, quisiera detenerme en el aspecto más evidente y humilde del cuerpo: su materialidad, pues si bien no hay forma de comprender el cuerpo (o los cuerpos) exonerado de los sentidos que se da a sí mismo y que le otorgan los otros, no podemos olvidar la condición primaria que hace posible todo lo demás. 
¿Qué posibilidades o sentido tendría la producción de imágenes entre seres inmateriales?

La experiencia profundamente corporal que traen consigo las animitas y el respeto que inspiran, desbordando incluso la noción de creyente y no creyente, me han llevado a explorar nuevos caminos para mirarlas desde otros ángulos. Por tal razón he tomado relativa distancia del marco hermenéutico de la Bildwissenschaft para situarme en un enfoque que diluye la distancia entre los cuerpos que crean imágenes y las imágenes mismas. Se trata de un salto hacia atrás, anterior a la atención que nos merece la relación entre los individuos y las imágenes, un enfoque que de alguna manera no contradice lo que he planteado hasta ahora, pero que lo fundamenta de otra forma.

Remontémonos, entonces, a principios del siglo xx, cuando el dualismo seguía siendo un problema tanto en el campo de la psicología como en el de la filosofía. En este último, el esfuerzo de Husserl se dirige justamente a superarlo pensando la conciencia en términos de relaciones: la conciencia y las cosas existen en relación. Al interior de la filosofía husserliana, para que haya imagen debe haber conciencia de imagen ${ }^{4}$.

Frente al mismo problema, Bergson va un paso más allá: no se trata de relaciones, no hay cosa ni hay conciencia, pues toda división de la materia en cuerpos independientes y absolutamente determinados es una división artificial: «Mi cuerpo es pues, en el conjunto del mundo material, una imagen que actúa como las demás, recibiendo y devolviendo movimiento, con esta única diferencia, quizás, que mi cuerpo parece elegir, en cierta medida, la manera de devolver lo que recibe» (Bergson, 2006: 35).

Diluida la distancia entre el sujeto y el objeto, en el pensamiento de Bergson las nociones de imagen, percepción y representación tienen un sentido y un estatuto distinto al fenomenológico y, desde luego, distinto de la ciencia de la imagen o Bildwissenschaft, asentada en la fenomenología y con inquietudes hermenéuticas ${ }^{5}$. En el pensamiento de Bergson, la imagen no puede entenderse solamente como «artefacto icónico». Un artefacto icónico sería, en

4. En Investigaciones lógicas, 5, Husserl comprende la conciencia como la estructura de análisis de lo que hay. La experiencia del mundo por parte del sujeto (la consciencia) depende de los «actos intencionales», entendiendo como tales un «estar dirigido hacia». El modo en que el sujeto se dirige hacia el objeto (el acto intencional) depende del modo en que este (el objeto) aparece. Se trata de una relación constitutiva por medio de la cual Husserl escapa del problema cartesiano de la jurisdicción cerrada de la consciencia. En este sentido, Bergson difiere radicalmente de la fenomenología.

5. «La primera característica a destacar en el enfoque hermenéutico es su motivación ontológica. Su interés primario está dirigido a desarrollar las preguntas elementales respecto al carácter propio y a las condiciones generales de aquello que es. A fin de plantear y esclarecer tales cuestiones, dicho enfoque se orienta, bajo influencia de la fenomenología, hacia el aparecer en la experiencia. Es posible reconstruir la tesis ontológica fundamental de tal enfoque en los siguientes términos: ser es aparecer con sentido. El término "sentido" se utiliza aquí para indicar la dimensión general de comprensibilidad, esto es, el trasfondo u horizonte desde el cual se articula el carácter significativo de todo aparecer en la experiencia» (Rubio, 2017: 10). 
efecto, una imagen, pero también todo lo que nos rodea y nosotros en cuanto cuerpos. Dice Bergson:

El fenómeno, la imagen, es lo que aparece en tanto aparece. Bergson nos dice, entonces, que lo que aparece está en movimiento y, en un sentido, es muy clásico. Lo que no es clásico es lo que saca de allí. Él toma en serio esta idea. Si lo que aparece está en movimiento, solo hay imágenes-movimiento. (Deleuze, 1981: 2)

El cuerpo es materia y es imagen porque es vibración y estremecimiento, una imagen-movimiento en un universo de imágenes-movimiento sujeta a la indeterminación: «Digan que mi cuerpo es materia o digan que es imagen, poco importa la palabra. Si es materia forma parte del mundo material y el mundo material en consecuencia existe alrededor de él y más allá de él» (Bergson, 2006: 35). Ahora bien, el mismo Bergson ha dicho que el cuerpo («mi cuerpo») es una imagen distinta de las demás. Señala Deleuze:

Para Bergson, la desviación, el intervalo, bastará para definir un tipo de imágenes entre las otras, pero con una particularidad: la de ser imágenes o materias vivas. Mientras que las otras imágenes actúan y reaccionan sobre todas sus caras y en todas sus partes. Aquí tenemos imágenes que no reciben acciones sino sobre una cara o en determinadas partes, y no ejecutan reacciones más que en y mediante otras partes. Son imágenes en cierto modo descuartizadas. Y, en primer lugar, su cara especializada, que después recibirá el nombre de receptiva o sensorial, ejerce un curioso efecto sobre las imágenes influyentes o las excitaciones recibidas: es como si aislara algunas entre todas las que concurren y coactúan en el universo. (Deleuze, 1984: 95)

Nuestro cuerpo percibe, esto quiere decir que entra en relación con la materia, con las demás imágenes haciendo uso de sus caras especializadas. Inserta - la percepción - en la materia, solo se orienta a la acción como efecto de las acciones que recibe. El cuerpo percibe lo que le es dado percibir, "discierne», por ejemplo, entre todas las posibilidades que ofrece la luz, aquellas longitudes de onda que le permiten actuar en la materia. La percepción guarda con la materia, con las imágenes, una relación constitutiva. El propio Bergson señala: «Llamo materia al conjunto de las imágenes, y percepción de la materia a esas mismas imágenes relacionadas con la acción de una cierta imagen determinada, mi cuerpo» (Bergson, 2006: 37).

La imagen, en ese sentido, puede verse como la materia en su conjunto y, a su vez, como la materia que integra mi cuerpo junto a mis percepciones. Miguel Ruiz (2013) lo sintetiza de la siguiente forma:

Las imágenes jugarían, en términos muy generales, un rol de expresión de los elementos virtuales o potenciales de un universo material. Estos elementos integrados en una serie de imágenes devienen a la vez en la condición de ser habilitantes de la percepción, la cual selecciona los objetos de toda representación efectiva. En la medida en que son elementos del todo de la materia, las imágenes tendrían una realidad independiente de nuestra percepción, pero 
al mismo tiempo comprenderían el todo de una percepción. Además, atendiendo a la implicación por definición entre la materia y la imagen, las partes seleccionadas por nuestra percepción se presentarán en todos los casos según nuestras necesidades, y se ajustarán en cada caso a un aspecto relativo a la satisfacción de estas. De este modo la materia o el contenido material de las imágenes es real y exterior a nosotros, pero su silueta o forma es imaginaria y, en consecuencia, relativa a nosotros. Así debemos comprender ese más y ese menos: más que la mera representación intelectual de objetos, menos que la cosa en cuanto tal. (Ruiz, 2013: 104)

Ahora bien, una percepción pura, orientada exclusivamente al movimiento, no podría producir nada que difiriera del movimiento, por ello, entre la percepción y la acción, Bergson intercala un componente activo, la afección, «una impresión sobre nuestro cuerpo que nos sugiere alguna reacción» (Martin, 2010: 61). Nuestro cuerpo, como centro de acción, es también asiento de afección, de manera que la interioridad y la exterioridad pueden comprenderse como una relación entre imágenes, toda vez que «la percepción coincide con el objeto percibido» (Bergson, 2006: 82).

Pero esta subjetividad delineada por la percepción, la afección y la acción no es un atributo exclusivo de los seres humanos, sino que la compartimos con otros organismos complejos. Lo que nos diferencia de ellos es que no solo percibimos la materia y nos conmocionan sus afecciones, sino que en el movimiento indivisible de la materia también tenemos conciencia de ello. Bergson (2006) se pregunta: «¿De dónde proviene el hecho de que esta percepción sea consciente, y por qué todo sucede como si esta conciencia naciera de los movimientos interiores de la sustancia cerebral?». Luego responde: «no hay percepción que no esté impregnada de recuerdos. A los datos inmediatos y presentes de nuestros sentidos les mezclamos miles de detalles de nuestra experiencia pasada» (Bergson, 2006: 44), como señala Deleuze:

Hemos visto que la subjetividad se manifestaba ya en la imagen-movimiento: surge en cuanto hay una variación entre un movimiento recibido y un movimiento ejecutado, entre una acción y una reacción, entre una excitación y una respuesta, entre una imagen-percepción y una imagen-acción. Y si la afección es también una dimensión de esta primera subjetividad, ello se debe a que pertenece a la variación, constituye su "adentro", la ocupa en cierto modo, pero sin llenarla o colmarla. Ahora, por el contrario, la imagen-recuerdo viene a llenar la variación, la colma efectivamente, de tal manera que nos devuelve individualmente a la percepción en lugar de prolongarla en movimiento genérico. La imagen-recuerdo saca provecho de la variación, la supone, puesto que se inserta en ella, pero su naturaleza es otra. La subjetividad cobra, pues, un nuevo sentido que ya no es motor o material sino temporal y espiritual: lo que «se añade» a la materia, y no lo que la distiende; la imagen-recuerdo, y no ya la imagen-movimiento. (Deleuze, 1987a: 72)

Volviendo sobre el problema del dualismo, Materia y memoria (2006), la obra donde Bergson despliega su esfuerzo por resolver los problemas que plan- 
tea, tiene como subtítulo Ensayo sobre la relación del cuerpo con el espiritu, en lo que parece una abierta contradicción. De hecho, el mismo autor señala: «Este libro afirma la realidad del espíritu y la realidad de la materia, e intenta determinar la relación entre ambas a través de un ejemplo preciso, el de la memoria. Él es, pues, netamente dualista» (Bergson, 2006: 25). Se trata en efecto de dualismo, pero de un dualismo con el que espera poner fin a las dificultades de la oposición entre realismo e idealismo por medio de su concepción de la materia. Como se ha dicho, Bergson concibe la materia y el conjunto del universo como imagen, y a nuestro cuerpo también como una imagen inserta en ella. Como tal, nuestro cuerpo, nuestro cerebro sería incapaz de producir representaciones de la materia de la que forma parte. Eso por un lado. Por otro, la memoria que posibilita la conciencia, con el recuerdo que actúa en el presente:

Con todo, no hay estado de alma, por simple que sea, que no cambie en cada instante, ya que no hay conciencia sin memoria, ni continuación de un estado sin la adición, al sentimiento presente, del recuerdo de los momentos pasados. En esto consiste la duración. La duración interior es la vida continua de una memoria que prolonga el pasado en el presente, sea que el presente contenga distintamente la imagen del pasado que se agranda sin cesar, sea que más bien testifique, por su continuo cambio de cualidad, la carga cada vez más pesada que uno arrastra detrás de sí, a medida que la vejez aumenta. Sin esta supervivencia del pasado en el presente no habría duración, sino solamente instantaneidad. (Bergson, 1960: 27)

Sin el concurso de la memoria, el presente sería un pellizco de tiempo, un mínimo de la duración en la materia imposible de asir. Ahora bien, situado el cuerpo en la línea de la materia y orientado totalmente a la acción y el presente, no podría albergar la memoria. Esto implica, por cierto, al cerebro, pues siendo materia como el cuerpo del que forma parte "no puede tener ninguna diferencia de naturaleza con los demás estados de la materia; todo en él es movimiento como en la percepción pura que determina» (Deleuze, 1987b, 54). ¿Dónde residen entonces los recuerdos?

La memoria no tiene pues necesidad de explicación. O más bien, no hay facultad especial cuyo rol sería retener del pasado para verterlo en el presente. El pasado se conserva por sí mismo, automáticamente. Desde luego, si cerramos los ojos a la indivisibilidad del cambio, al hecho de que nuestro más lejano pasado se adhiere a nuestro presente y constituye, con él, un único y mismo cambio ininterrumpido, nos parece que el pasado pertenece normalmente a lo abolido y que la conservación del pasado tiene algo de extraordinario: nos creemos obligados entonces a imaginar un aparato cuya función sería registrar las partes del pasado susceptibles de reaparecer a la conciencia. Pero si tomamos nota de la continuidad de la vida interior y por consiguiente de su indivisibilidad, lo que se tratará de explicar ya no es la conservación del pasado, sino por el contrario su aparente abolición. Ya no tendremos que dar cuenta del recuerdo, sino del olvido. (Bergson, 2013: 172) 
Los recuerdos, esas imágenes del pasado, no se encuentran en ningún lugar del cuerpo sino en la duración, una dimensión ontológica donde la memoria integral accede como respuesta al llamado del presente que percibe ${ }^{6}$. Incluso aquel recuerdo que como hábito registramos en nuestra corporalidad (como cuando conducimos un automóvil o andamos en bicicleta), se actualiza solo por medio de un llamado del presente a la memoria.

Ahora bien, la "percepción pura» encadenada a la materia y el «recuerdo puro» que pone de manifiesto la realidad de la duración existen más de derecho que de hecho ${ }^{7}$, pues el despliegue de toda experiencia se da en su «impureza»: «la propia imagen-recuerdo reducida al estado del recuerdo puro permanecería ineficaz. Virtual, ese recuerdo no puede devenir actual más que por la percepción que lo atrae. Impotente, toma su vida y su fuerza de la sensación presente en que se materializa» (Bergson, 2006, 139).

La conciencia es memoria actuante en el presente que se proyecta al futuro solo en la medida en que encuentra su anclaje en un cuerpo, por eso: «La duración es esencialmente memoria, conciencia y libertad y es conciencia y libertad porque es memoria» (Deleuze, 1987b: 47).

Vuelvo entonces al núcleo de mi investigación. En el universo abierto de imágenes-movimiento no hay dirección ni sentido, nada que pueda preverse en la indeterminación de múltiples acciones y reacciones posibles entre las imágenes-movimiento. Por ello, por nuestros cuerpos y las múltiples afecciones que registra, y de las cuales somos conscientes, devolvemos a ese universo nuevas imágenes (materiales) que le dan sentido.

Los seres humanos, desprendidos del mundo por el intervalo en la duración que introduce nuestro cerebro, hemos hecho de las imágenes un modo de resistir lo dado «tal y como es» y retornar al mundo (re)construyéndolo. Bien lo señala Deleuze respecto del cine:

Solo la creencia en el mundo puede enlazar al hombre con lo que ve y oye. Lo que el cine tiene que filmar no es el mundo, sino la creencia en este mundo, nuestro único vínculo. Se preguntó a menudo por la naturaleza de la ilusión cinematográfica. Volver a darnos creencia en el mundo, ese es el poder del cine moderno (cuando deja de ser malo). Cristianos o ateos, en nuestra universal esquizofrenia «necesitamos razones para creer en este mundo». (Deleuze, 1987a: 229-230)

6. La memoria ontológica se vuelve memoria psicológica, señala Bergson, por medio de un llamado del presente: «la memoria integral responde al llamado de ese estado presente a través de dos movimientos simultáneos, uno de traslación, por el cual se presenta entera al encuentro de la experiencia contrayéndose más o menos de este modo, sin dividirse, en vista de la acción; el otro de rotación sobre sí misma, por el cual se orienta hacia la situación del momento para presentarle la cara más útil» (Bergson, 2006: 180).

7. Bergson mismo señala: «Pediremos que se entienda provisoriamente por percepción no mi percepción concreta y compleja, aquella que es hinchada por mis recuerdos y que ofrece siempre un cierto espesor de duración, sino la percepción pura, una percepción que existe de derecho más que de hecho, la que tendría un ser situado donde soy, viviendo como vivo, pero absorbido en el presente, y capaz de obtener de la materia, a través de la eliminación de la memoria bajo todas sus formas, una visión a la vez inmediata e instantánea» (Bergson, 2006: 31). 
Las imágenes arrancan de un mundo material, del cual forma parte nuestro cuerpo y del cual no podemos separarnos por más absurdo que parezca, es un hecho que ocurre junto con la aparición de los seres humanos. Por eso, "por el absurdo, en virtud del absurdo" (Deleuze, 1987a: 227), surge lo impensado como potencia del pensamiento y se actualiza en imágenes. Las imágenes, esta vez como artefactos icónicos, son, desde este punto de vista, imágenes donde se concentran una multiplicidad de duraciones que invoca cierto presente o diversos presentes que se actualizan.

Entonces, en el universo de imágenes-movimiento es posible comprender la producción de artefactos visuales como registros de las afecciones del mundo en los cuerpos que, a su vez, son devueltos al mundo como novedades que le dan sentido. Nuestra autopercepción como seres corpóreos es aquí fundamental: «¿Cómo deshacernos de nosotros mismos, y deshacernos a nosotros mismos?», se pregunta Deleuze (1984: 101) a propósito de Film (1963), el cortometraje de Beckett. ¿Cómo, además, deshacernos de la experiencia registrada en nuestra corporalidad? Al percibirnos como cuerpos, organismos circunscritos y a la vez abiertos, la «frontera» entre el uno mismo (self) y las demás imágenes-movimiento siempre será problemática: «¿Quién podría decir dónde comienza y dónde termina la individualidad, si el ser vivo es uno o varios, si son las células las que se asocian en organismo o si es el organismo el que se disocia en células?» (Bergson, 1963: 434) .

¿Quién podría definir entonces la frontera que nos separa no solo del mundo, sino también de los demás, de los seres humanos que participan de nuestra vida?

$\mathrm{Si}$, como se observa en la obra de Bergson, los cuerpos son menos independientes de lo que el pensamiento occidental ha querido, si nuestras divisiones no son más que demarcaciones habilitadas por la memoria y la percepción profunda del propio ser, entonces la muerte de un miembro de la comunidad la experimentaríamos como una desgarradura en la propia corporalidad. La muerte, como paradigma en la creación de imágenes como ha pensado Belting (2009a, 2009b), tiene por una parte su origen en el cuerpo herido por la ausencia, pero también en la duración que conforma nuestra conciencia y nos hace saber que hemos perdido "algo», tal es la razón por la cual, me parece, desde el principio «los seres humanos se vieron tentados a comunicarse con las imágenes como si fueran cuerpos vivos y también a aceptarlas en el lugar de esos cuerpos» (Belting, 2009b: 157).

Pero, además, la experiencia de la muerte por medio de otro trae consigo la inminencia del propio fin. De todos los seres vivos el ser humano es el único que tiene la capacidad de reflexionar sobre su finitud por la certeza que tiene

8. El pensamiento de Bergson tiene una proximidad mayor al pensamiento andino. La familia extendida que comprende el ayllu no son solo hombres, mujeres y niños unidos por lazos de sangre y reciprocidad; son también las plantas, la tierra y las criaturas que la habitan, visibles y no visibles para cualquier ojo, sensibles y no sensibles para cualquier cuerpo. 
de su muerte. Esto conlleva la reflexión sobre nosotros en relación con aquello que somos, más allá de lo que hacemos y experimentamos.

A causa de la muerte el cuerpo es sacado de la superficie donde participa de la vida: las comunidades lo hunden en la tierra, lo esconden en nichos o lo deshacen en cenizas para resguardo de la higiene, pero también para alejar de la mirada el impacto de la descomposición. La tumba, como artefacto visible, pugna en sentido contrario: pone a la vista el ser que es por obra de la memoria.

Pero la pregunta nos acecha: ¿dónde va a dar esa duración que nos permite percibirnos como "nosotros mismos» cuando morimos? ¿'Dónde queda nuestro tiempo? ¿Qué sentido puede tener la muerte para la única imagenmovimiento que sabe de sí? "Lo que todas las creencias tienen en común es que de alguna manera se oponen a nuestra aparente finitud progresando por encima de todo lo visible hacia lo invisible y de lo sensible a lo suprasensible. La tumba es un testimonio manifiesto precisamente de esta tendencia» (Jonas, 1998: 51).

Si nuestro cuerpo puede producir alteraciones en la materia contrayendo la duración y lo propio de la conciencia es hacer cuerpo en las imágenes (Ruiz, 2013), entonces la conciencia se hace cuerpo en las imágenes mortuorias, como las animitas, en un sentido simple cuando las percibimos y en un sentido fuerte cuando las creamos. El significado de representación tiene esa doble connotación.

Las imágenes mortuorias, desde la tumba hasta las fotografías que acompañan a los deudos, tienen una función similar: re-presentar (en el sentido reforzativo de la partícula re-) una duración que se ha perdido en tanto no hay un cuerpo que pueda acceder a ella. En la imagen mortuoria tenemos una duración que no puede hacerse presente, sino por medio de un artefacto icónico realizado por los que se niegan a perderla. Su elaboración es, en cierta manera, un modo de restituir, de hacer próxima a los cuerpos que quedan, esa duración que se encarnaba en un cuerpo que se ausenta en tiempo presente.

\section{II}

Volvamos, pues, a las animitas partiendo de aquello que "salta a la vista».

La primera característica de las animitas es su diversidad y, sin embargo, poder ser reconocidas como tales por quienes participan de la cultura chilena. Pese a todas sus variaciones, las animitas no son confundidas con otra cosa?

La segunda característica es su permanente transformación. Es difícil ver una animita igual a sí misma, aunque también es difícil percibir el cambio en

9. Más que una estética determinada, entra en juego aquí una estructura de contrastes que se abre en el espacio público habitual: generalmente se presenta una estructura básica («arquetipo») rodeada y/o cubierta de objetos que forman parte del mundo privado de las personas. Vistos de manera aislada, cualquiera de estos objetos nos parecería perdido, pero al encontrarse agregados estructuralmente, podemos «saber» que son de «alguien» (un ánima) o que «forman parte de alguien» (del cuerpo del ánima). En el caso de las animitas abandonadas, predomina en su reconocimiento el arquetipo de casa o la cruz (González, 2017). 
ellas. Las vemos a diario y solo el paso del tiempo nos lleva a distinguir sus transformaciones.

En tercer lugar, las animitas se respetan. En Chile pocas personas tomarían resueltamente los objetos de una animita, independientemente de que se adhieran o no a la práctica o a la creencia de lo que habitualmente llamamos «sobrenatural». Las animitas exigen un tratamiento respetuoso, incluso estando en ruinas.

Finalmente, las animitas no están sujetas a ninguna determinación desde su origen. Nadie puede predecir el momento ni el lugar de una muerte, menos en el espacio público, porque es, de suyo, indeseada. Sin una institución que las regule, las animitas se corresponden con las imágenes interiores y la multiplicidad de duraciones de quienes las erigen y participan de ellas, incluso más que con el propio difunto ${ }^{10}$. Poseen, además, esa «vulgaridad orgánica» que menciona Didi-Huberman (2013) y son resistentes a todo discurso de artisticidad o autoría. Cada exvoto, cada ofrenda que se le agrega, no se basa en consideraciones compatibles con la comprensión más tradicional del arte, como tampoco con las religiones formales, y aunque no necesariamente las excluye, el trasfondo de cada una es independiente y afectivo.

Pero ¿qué son las animitas «realmente»? Si consideramos la manera en que Bergson entiende la totalidad de lo real, son imágenes-movimiento como lo es el cuerpo de cualquiera de nosotros. También son artefactos icónicos, pues instituyen sentido en lo real por obra de la memoria que nos da la libertad de devolver al universo de las imágenes-movimiento nuestras afecciones, interviniéndolo. Son imágenes que, además, concentran un plexo de duraciones, porque a diferencia de otras imágenes circunscritas a cuerpos mediales inertes (una pintura, una fotografía, por ejemplo) la animita refuerza su indeterminación original en el libre ejercicio de los practicantes y devotos. Son cuerpos (Lira, 2015; González 2017): cada animita es sentida como una presencia y recibe atenciones y cuidados relativos al cuerpo mientras la memoria la mantenga viva ${ }^{11}$. Son cuerpos en movimiento, cambiantes y abiertos a fuerzas que las desorganizan y las reorganizan cada vez como otro cuerpo (Ulm, 2018: 31).

La vida de las animitas (metafóricamente hablando) es tan azarosa e impredecible como la vida de sus hacedores y practicantes. Sujetas a la lógica reciprocitaria del mundo andino que se actualiza en ellas, su existencia y «bienestar» depende de la relación que establezca con sus devotos: como los riwutus, las animitas son favorables a los vivos siempre y cuando reciban un tratamiento religioso apropiado ${ }^{12}$. A su vez, las atenciones que reciba una animita serán

10. Al entrevistar a sujetos practicantes de la animita, no es extraño encontrar distintos relatos de la vida y de la muerte del difunto. Relatos que escapan de la realidad misma de los hechos y que también resultan contradictorios entre sí.

11. La presencia de objetos relativos a la vida diaria y a la satisfacción de necesidades básicas, como alimentos y bebidas, por ejemplo, expresa el cuidado y el tratamiento propios de los cuerpos vivos.

12. Me parece importante comprender la palabra religión a partir de su etimología. El radical leg- que soporta el verbo legere ('escoger'), forma también neg-legere y di-legere, que le apor- 
proporcionales a su capacidad de responder a quienes recurren a ellas en busca de milagros. La relación entre una animita y sus devotos es en clave de reciprocidad $^{13}$, de manera que el crecimiento orgánico y la «buena salud» que experimenten dependerán del cuidado «diligente» de sus devotos, pudiendo morir a causa de la «negligencia» y del abandono.

La creación de una animita, desde luego, tiene que ver con el cuerpo del difunto, la huella de su caída en un lugar del espacio público y la duración perdida con la muerte, pero también, y sobre todo, con la memoria y los cuerpos de quienes le sobreviven. Las animitas - $-\mathrm{y}$ esto es extensivo a toda imagen mortuoria- se originan en la limitación extrema de los cuerpos humanos: la finitud, la inminente vuelta a la tierra donde se diluyen los órganos y ese intervalo que somos pierde sus contornos hasta quedar irreconocible. Son producidas por la consciencia que se resiste y se interroga una y otra vez por el sentido de lo irreparable que viene a ser la muerte. El ser humano necesita comprenderse por medio de especulaciones interrogativas, señala Jonas, «de las tumbas se levanta la metafísica. Pero también lo hace la historia, entendida como recuerdo de lo pasado, como lo muestra primero el culto a los antepasados. La conservación del vínculo con ellos amplía el ahora pasajero de la propia existencia» (Jonas, 1998: 51-52).

Es la conciencia de nuestra subjetividad, el poder de diferenciarnos en el universo de las imágenes-movimiento, la que nos lleva a «intuir» mundos o trasmundos que exceden la finitud. Se trata de un tipo de intuición derivada de una negativa contra la evidencia material alojada en la persistencia de la memoria la que señala que hay algo más allá, algo que no va ligado perfectamente a la "experiencia de nuestra motricidad" y que trasciende la experiencia psicológica acoplada al cuerpo, dice Deleuze (1987a: 59) citando a JeanLouis Schefer.

La tumba, la animita y otras imágenes mortuorias ponen a la vista la duración de una ausencia que es sentida en tiempo presente. Son la finitud consumada y sin sentido actualizando el pasado entre la materia que permanece en acto.

$\mathrm{El}$ «más allá» del que una animita participa no es un lugar, sino la configuración colectiva y situada de la duración, un espacio y un momento de creación que enlaza a los sujetos con la totalidad del universo desde su finitud. Son actos de reconciliación con la materia de la que formamos parte y que no podemos abarcar en su totalidad desde el momento en que podemos ser conscientes.

tan respectivamente un sentido negativo y otro positivo (Moreno, 2000): «A estos verbos corresponden los sustantivos neg-ligentia y di-ligentia [...] En re-ligio el prefijo re-cumple la misma función reforzativa que en re-spicio, re-vereor. Religio es entonces "tomar atentamente en consideración" " (Moreno, 2000: 1).

13. Una de las características del mundo andino es la reciprocidad: «la reciprocidad, por ejemplo, es como un cordón umbilical que nutre a las personas por él vinculadas, ya que existe un constante y múltiple ir y venir entre los individuos relacionados por intercambios recíprocos» (Mayer, 1974: 39). La reciprocidad permea el mundo andino en toda su complejidad y multidimensionalidad. 


\section{Conclusión}

Del mixto de materia y memoria afloran la conciencia y la representación. En consecuencia, la libertad de la cual disponemos los seres humanos proviene del recuerdo, de aquella imagen registrada en lo pretérito que nos devuelve a la percepción como un particular que puede intervenir en el universo de las imágenes-movimiento, cambiando su dirección y dotándolo de sentido. El proceso de creación de artefactos icónicos —o imágenes en el sentido habitual de la palabra- y nuestra necesidad de relacionarnos con ellos tiene directa relación con este asunto.

El vínculo entre la animita y la tumba tiene que ver con dos cuestiones fundamentales: en primer lugar, con la reflexión sobre el sí mismo al que Jonas (1998) hace referencia con la tumba; sin embargo, la animita carece de cuerpo (de cadáver) ${ }^{14}$, pues toma su lugar como cuerpo simbólico.

En segundo lugar, tiene relación con esta apertura a la «eternidad» desde la finitud, pero dicha "eternidad» no es sino un cúmulo de duraciones que se abren en torno a una memoria que ha quedado sin cuerpo y que la comunidad se resiste a perder. En el sentido que Bergson nos abre, son actos de libertad que intervienen en la materia, porque es una exigencia de los cuerpos vivos, cuerpos humanos que no se consumen sobre su propia materialidad.

El pasado ontológico no solo adquiere existencia psicológica. A través de las imágenes alojadas en sus cuerpos mediales las invocaciones se materializan y se actualizan continuamente. Las animitas chilenas son solo un ejemplo de ello.

Similar a lo que ocurre con los cuerpos vivos de quienes las practican, nadie puede predecir el curso de la vida de una animita, tampoco su desenlace. Es posible reconocer el momento en que se demarca su espacio, ser testigos de la instalación de los primeros materiales y de su primera forma, pero nadie puede saber si se mantendrá dentro de estos lindes o si crecerá hasta desbordarlos; tampoco es posible saber si será milagrosa y venerada por largo tiempo o si pronto quedará en el olvido. Por su condición y propiedades de cuerpo, la animita es pura indeterminación.

La animita es una imagen-movimiento inserta en un universo de imágenesmovimiento nutrido histórico y culturalmente modelado, por eso también es un artefacto icónico. Todas son, por cierto, cuerpos sujetos a las afecciones de otros cuerpos que las animan de manera tal que es difícil para el investigador presentarlas en la complejidad de sus cambios y su duración, pues en las animitas converge el tiempo interno - el tiempo que es propio de los individuos-, así como el tiempo intuido por un grupo histórica y espacialmente situado.

La animita, en definitiva, puede comprenderse como un sintetizador, un entramado de fuerzas significantes que sin lugar a dudas no están unificadas en un sujeto, sino en un conjunto de sujetos que realizan esa significación en un contexto definido por herencia andina y católica.

14. En Chile, vale decir, existen animitas-tumba, es decir, tumbas que se transforman en animitas por la relación que establecen los creyentes con ellas. En esta investigación las he dejado fuera por la doble complejidad que presentan. 


\section{Referencias bibliográficas}

Bahamondes, L. (2002). «Transfiguración en el relato de la animita». Revista de Lengua y Literatura Mapuche, 10, 53-62. Universidad de la Frontera. Recuperado de <http://publicacionescienciassociales.ufro.cl/index.php/ indoamericana/article/viewFile/510/430>.

- (2014). Del anonimato marginal al reconocimiento popular: Representaciones de delincuentes animitizados. Recuperado de <http://repositorio.uchile.cl/ bitstream/handle/2250/138257/Del-anonimato-marginal-al-reconocimiento-popular.pdf? sequence $=1$ \&isAllowed $=y>$.

BAsCopé, V. (2001). «El sentido de la muerte en la cosmovisión andina: el caso de los valles andinos de Cochabamba». Chungará (Arica), 33 (2), 271-277. <https://dx.doi.org/10.4067/S0717-73562001000200012>

Belting, H. (2009a). Imagen y culto: Una historia de la imagen anterior a la edad del arte. Madrid: Akal.

- (2009b). Antropología de la imagen. Buenos Aires: Katz Editores.

- (2015). «Imagen, medium, cuerpo: Un acercamiento a la iconología». Cuadernos de Información y Comunicación, 20, 153-170. <http://dx.doi.org/10.5209/rev_CIYC.2015.v20.49382>

Benavente, A. (2011). "Las "animitas": Testimonio religioso e histórico de piedad popular en Chile. Estudios atacameños». Arqueología y Antropología Surandina, 41, 131-138. <http://dx.doi.org/10.4067/S0718-10432011000100008>.

Bergson, H. (1960). Introducción a la Metafísica. Ciudad de México: Centro de Estudios Filosóficos Universidad Nacional Autónoma de México.

- (1963). «La evolución creadora». En: Obras Escogidas. Madrid: Aguilar.

- (2006). Materia y memoria. Buenos Aires: Cactus.

- (2013). El pensamiento y lo moviente. Buenos Aires: Cactus.

Boenм, G. (2010). «Iconoclasmo: Borrado - Superación - Negación». En: Cómo producen sentido las imágenes: La fuerza del mostrar. Berlín: Berlin University Press, 2014, 54-71. Traducción: Roberto Rubio. [Documento de uso exclusivo para el magíster en Filosofía de la Universidad Alberto Hurtado.]

- (2011). «La diferencia icónica». Rheinsprung 11: Zeitschrift für Bildkritik, 2014, 170-175. Traducción: Roberto Rubio. [Documento de uso exclusivo para el magíster en Filosofía de la Universidad Alberto Hurtado.]

Deleuze, G. (1981). «Sur le cinéma : l'image-mouvement et l'image-temps». Curso Vincennes - St Denis : Bergson, proposiciones sobre el cine Cours du 18/05/1982. Traducido por Ernesto Hernandez B. Recuperado de $<$ https://www.webdeleuze.com/textes/80>.

- (1984). La imagen-movimiento: Estudios sobre cine 1. Barcelona: Paidós.

- (1987a). La imagen-tiempo: Estudios sobre cine 2. Barcelona: Paidós.

- (1987b). El bergsonismo. Madrid: Cátedra.

Didi-Huberman, G. (2013). Exvoto: Imagen, órgano, tiempo. Vitoria-Gasteiz: Sans Soleil. Recuperado de <https://www.sanssoleil.es/exvotos-imagenorgano-tiempo-de-didi-huberman-descarga-gratuita/>. 
García Varas, A. (2011). «Lógica(s) de la imagen». En: Filosofía de la Imagen. Salamanca: Ediciones Universidad de Salamanca.

Guerrero, B. (2012). «La presencia de la animita en el relato salitrero del norte grande de Chile». Márgenes, 9 (10), 19-24. Recuperado de <https:// www.academia.edu/36960435/La_presencia_de_la_animita_en_el_relato_salitrero_del_norte_grande_de_Chile>.

González, M. (2017). Bicianimitas: un análisis desde el giro icónico. Tesis para optar al grado de Magister en Filosofía, Universidad Alberto Hurtado, Santiago.

Jonas, H. (1998). «Herramienta, imagen y tumba». En: Pensar a Dios y otros ensayos. Barcelona: Herder

Lindán, A. (2007). «Los imaginarios urbanos y el constructivismo geográfico: los hologramas espaciales». EURE (Santiago), 33 (99), 31-46. $<$ https://dx.doi.org/10.4067/S0250-71612007000200004>

Lira, C. (1999). «La animita en el ámbito del arte». Aisthesis, 32, 74-97.

- (2002). El rumor de las casitas vacías: Estética de la animita. Santiago de Chile: Ediciones de la Pontificia Universidad Católica de Chile.

- (2009). «La animita: Historia y diseño». Revista 180, 23, 20-23. <http://dx.doi.org/10.32995/rev180.Num-23.(2009).art-248>

- (2015). «Acerca de la experiencia estética y el valor de las subjetividades». Scanner Cultural. Recuperado de <https://revista.escaner.cl/node/7704>.

- (2016). «Las cruces de la mala muerte en la costa norte del Perú». En: LiRA, C. Lecturas de la animita. Santiago de Chile: Ediciones de la Pontificia Universidad Católica de Chile, 75-90.

Martin, J. (2010). «La imagen-movimiento: Deleuze y la relación Beckett-Bergson». Areté: Revista de Filosofía, XXII (1), 51-68. Recuperado de $<\mathrm{http} / / /$ www.scielo.org.pe/pdf/arete/v22n1/a03v22n1>.

MAYER, E. (1974). «Las reglas del juego en la reciprocidad andina». En: AlberTI, G. y MaYer, E. (comp.). Reciprocidad e intercambio en los Andes peruanos. Lima: IEP Ediciones.

Moreno, J. (2000). La noción de religión. Santiago: Centro de Estudios Judaicos. Universidad de Chile. [Documento de uso exclusivo para el diplomado en Ciencias de la Religión.]

Moxey, K. (2009). «Los estudios visuales y el giro icónico». Estudios Visuales: Ensayo, Teoría y Crítica de la Cultura Visual y el Arte Contemporáneo, 6, 8-27. Recuperado de <https://dialnet.unirioja.es/servlet/articulo?codigo= $3018364>$.

OJedA, L. (2011). «Hologramas de la muerte imprevista: Pregnancia urbana de las animitas en Chile». Geograficando, 7 (7), 69-88. Recuperado de $<$ http://www.memoria.fahce.unlp.edu.ar/art_revistas/pr.5092/pr.5092. pdf $>$.

- (2013). «Animitas: apropiación urbana de una práctica mortuoria ciudadana e informal». Nueva Antropol, 26 (79), 99-121. Recuperado de $<$ https://www.nuevantropologia.org.mx/index.php/osjdata_na/article/ view/464>. 
Ojeda, L. y Torres, M. (2011). Animitas: Deseos cristalizados de un duelo inacabado. Santiago de Chile: Consejo Nacional de la Cultura y las Artes. Fondo Nacional de Desarrollo Cultural y de las Artes.

Parker, C. (1992). Animitas, machis y santiguadoras en Chile. Santiago de Chile: Rehue.

Plath, O. (2012). L'Animita: Hagiografía folclórica. Santiago de Chile: Fondo de Cultura Económica.

Readi, P. (2016). "Origen e historia de la animita». En: LiRA, C. Lecturas de la animita: Estética, identidad y patrimonio. Santiago de Chile: Pontificia Universidad Católica de Chile, 17-36.

Rubio, R. (2015). «El lugar de la fenomenología en el debate de la reciente filosofía de la imagen». Veritas, 33 (septiembre), 89-101.

- (2017). «La reciente filosofía de la imagen: Análisis crítico del debate actual y consideración de posibles aportes». Ideas y Valores, 66 (163), 273-298. <https://doi.org/10.15446/ideasyvalores.v66n163.51068>

RuIz, M. (2013). Tiempo y experiencia. Santiago de Chile: Fondo de Cultura Económica.

Salas, R. (1992). «Violencia y muerte en el mundo popular: Reflexiones en torno al simbolismo de las ánimas». Estudios sobre las Culturas Contemporáneas, IV (14), 181-192. Recuperado de <https://www.redalyc.org/ $\mathrm{pdf} / 316 / 31641411 . \mathrm{pdf}>$.

SpInozA, B. (1677). Ética. Madrid: Editora Nacional de Madrid, 1980.

UlM, H. (2018). "De la performance a la literatura: Aproximaciones a un pensamiento de los cuerpos». Hispanic Studies Review, 3 (2), 30-46. Recuperado de <https://hispanicstudiesreview.cofc.edu/issues/vol3_no2_2018/ 04-hsr-vol-3-no-2-2018-ulm.pdf>.

Wiesing, L. (2005). «Las principales corrientes de la actual filosofía de la imagen». En: Wiesing, L. Artifizielle Präsenz. Studien zur Philosophie des Bildes. Fráncfort: Suhrkamp, 17-36. Traducción: Roberto Rubio. Para uso en el curso "Pensamiento e imagen" (Universidad Alberto Hurtado, 2014). 
Macarena Soledad González Franzani es profesora de Historia, magíster en Filosofía y Doctora en Filosofía mención Estética y Teoría del Arte en la Universidad de Chile. Desde 2016 ha enfocado sus estudios en imágenes mortuorias de Chile, principalmente en animitas y fotografías de detenidos desaparecidos de la dictadura chilena. Ha sido ganadora de los concursos Becas Chile Crea (2020) y Fondart ${ }^{15}$ Nacional (2020) del Ministerio de las Culturas, las Artes y el Patrimonio de Chile.

Macarena Soledad González Franzani is a History lecturer, and has a Master's degree in Philosophy and $\mathrm{ahD}$ in Philosophy specialising in Aesthetics and Art Theory at the University of Chile. Since 2016 her academic focus has been on Chilean mortuary images, mainly animitas (roadside shrines to accident victims) and pictures of disappeared detainees of the Chilean dictatorship. She has been awarded a Chile Crea grant (2020) and a Fondart Nacional grant (2020) from the Ministry of Cultures, Arts and Heritage of Chile.

15. Fondo Nacional del Desarrollo Cultural y las Artes. 